This item was submitted to Loughborough's Research Repository by the author.

Items in Figshare are protected by copyright, with all rights reserved, unless otherwise indicated.

\title{
'It has really amazed me what my body can now do': boundary work and the construction of a body-positive dance community
}

PLEASE CITE THE PUBLISHED VERSION

http://dx.doi.org/10.1080/17430437.2015.1073946

\section{PUBLISHER}

Routledge (@) Taylor \& Francis)

\section{VERSION}

AM (Accepted Manuscript)

\section{PUBLISHER STATEMENT}

This work is made available according to the conditions of the Creative Commons Attribution-NonCommercialNoDerivatives 4.0 International (CC BY-NC-ND 4.0) licence. Full details of this licence are available at: https://creativecommons.org/licenses/by-nc-nd/4.0/

\section{LICENCE}

CC BY-NC-ND 4.0

\section{REPOSITORY RECORD}

Hill, Joanne L., Rachel Sandford, and Eimear Enright. 2015. “it Has Really Amazed Me What My Body Can Now Do': Boundary Work and the Construction of a Body-positive Dance Community". Loughborough University. https://hdl.handle.net/2134/18678. 
Notice: This is the author's version of an article due for publication in Sport in Society (published by Routledge). The article has been peer-reviewed, though appears here in its prepublication format in lieu of the publisher's version of record.

'It has really amazed me what my body can now do': boundary work and the construction of a body-positive dance community

Dr Joanne Hill, University of Bedfordshire

Dr Rachel Sandford, Loughborough University

Dr Eimear Enright, University of Queensland

\title{
Acknowledgements
}

The research on which this paper is based was supported by funding from the School of Sport, Exercise and Health Sciences at Loughborough University. The authors gratefully acknowledge this financial support and would also like to recognise the invaluable contribution made by the Irreverent Dance community, in particular those individuals who were active participants in the research process.

\begin{abstract}
Boundaries around normative embodiments in physical cultures can be exclusionary if one's embodied identity does not 'fit'. Normative boundaries are particularly marked in codified forms of dance such as ballet. Moves towards body-positivity aim to challenge these normative boundaries by redefining what dancers' bodies can look like and how they should move. This paper stems from an appreciative inquiry undertaken with one such project, a gender-neutral, LGBTQ-friendly adult ballet school in the UK; a subcultural context that marks itself as distinct from broader cultures of dance. Interviews with learners are analysed through a Bourdieuian lens to explore the construction and maintenance of a body-positive subculture. Findings suggest that boundaries of ability were crossed, with celebration of all bodies' capabilities, and boundaries of normative gender expression were transformed through a commitment to gender-neutrality and LGBTQ-friendly behaviours. However, boundaries around technical and aesthetic norms, while shifted or challenged, ultimately remained in place.
\end{abstract}

Keywords: physical culture, dance, LGBTQ, gender-neutral, body-positive, appreciative inquiry. 
Kirk (1999, 66) defined the notion of physical culture as 'a range of practices concerned with the maintenance, representation and regulation of the body', which are centred on 'highly codified, institutionalized forms of physical activity'. Physical culture, manifested in texts, resources and spaces, provides discourses of the body with which people narrate or make sense of their movement (Hargreaves and Vertinsky 2007). Individuals produce 'appropriate' bodies through a series of repeated practices, which are relevant to the context, established over time and always in process. One focus in the construction and regulation of bodies is gender. The oppositional construction of the archetypal masculine body as strong and muscular, and the feminine body as slender and submissive (Bordo 1993; Connell 1995), can be noted as a gender-normative and heterosexual boundary that regulates behaviour, movement and embodied identity. The construction of ability in physical cultural spaces is also related to gender, with what counts as a highly able body being mediated by the gender performance of that body (Butler 1998). Some research in physical culture has focused on the challenges faced by individuals as they negotiate boundaries of gender, sexuality, and ability, providing a rich understanding of bodily dissatisfaction and disengagement from physical activity (Berg and Lahelma 2010; Wellard 2006).

Recently, there has been a growth in body-positive approaches, which purport to be about creating safe spaces for inclusivity and bodily acceptance (Sastre 2014). While physical cultures can be seen as bounded by regulatory body practices, Kretchmar's (2000) use of the generative concept of 'movement subcultures' to talk about meaning-intensive places, where participants construct personal and shared meanings within a commitment to mastering movement, offers a constructive way to examine the creation and maintenance of bodypositive spaces. Responding to Kretchmar's (2000) call for more research on movement subcultures, and to the relative dearth of literature on body-positive physical activity, this paper represents an effort to understand how one positive subculture has formed and flourished. Before discussing our case, we briefly outline the context within which this bodypositive, gender-neutral, and lesbian, gay, bisexual, trans and queer (LGBTQ)-friendly adult ballet school became necessary.

Codified forms of dance such as ballet have been a popular research space for understanding the construction of embodied (gendered) identities, conformity and body image (Langdon and Petraca 2010; Radell, Keneman, Adame and Cole 2014). The evidence suggests that dance can promote both positive and negative body image (Ravaldi, Vannacci, Bolognesi, et al. 2006; Wellard, Pickard and Bailey 2007). The 'traditional' perception that dance is intended for lean, graceful women has undoubtedly contributed to the norm that ballet dancers need to be thin and lithe to dance well (Aalten 2004; Langdon and Petraca 2010). Indeed the ballet environment has been found to encourage dancers to lose weight to meet this body norm (Ravaldi et al. 2006). Social stereotypes concerning bodily norms can also be applied to thinking about the construction of gendered ballet bodies. Risner (2002) points out that dance education is both heterosexist and silent on homophobia. The female ballet body is already feminised and heterosexualised within constructions of sex-gendersexuality (Youdell 2005), or what Butler (1993) calls the heterosexual matrix: the ideal female body in ballet is slender to reify feminine weakness, and dances with men to reify 
heterosexuality. The non-normative (non-heterosexual, non-cissexual, gender queer, and fat) is thus marginalised by ballet's dominant gendered body boundaries (Aalten 2004). Ballet has been defended as a site of agency where physical challenge achieves technical prowess, 'where physical excellence is valuated' (Aalten 2004, 274); yet the aesthetic still reproduces cultural norms of passivity in women that contrast with the valuing of strength in men. As a physical culture, ballet can be argued to support the creation of boundaries between physically excellent bodies and other (read inferior) bodies.

In contrast, research on community dance programmes (Burgess, Grogan and Burwitz 2006; Erfer and Ziv 2006; Houston 2005) suggests that dance may contribute to building a sense of body empowerment. At their heart, many of these community dance programmes aim for social inclusion and they provide rich data on how dance has been used and received in projects targeted at transforming and empowering disenfranchised communities and individuals (Bartlett, 1996; Houston 2005). As community dance commentator Anthony Peppiatt (1996, 8-9) remarks:

The most central place of radical value and meaning within community dance at this time [...] lies in the body as site. The powerful and transforming experience of discovering pleasure through movement and through the body, of developing physical abilities, of expanding the physical imagination, and of a new liberation of the physical, mental, emotional, and spiritual self.

While any declarations of transformation and empowerment should be interpreted with a degree of caution, dance scholars at least seem confident that dance can provide a context where body positivity is a realisable pursuit (Houston 2005). Dance can, therefore, be a space in which participants can challenge and rewrite the boundaries and meanings of their physical culture through the co-construction of shared localised values (Kretchmar 2000). Considering this, we draw on the following theoretical framework to explore how body positivity was created and maintained within the context of the dance community at the heart of this research.

\section{Boundary shifting, crossing and transforming in Bourdieu's concept of habitus}

Within this paper, our thinking is informed by theoretical approaches that help us consider the links between the body, physical cultures and the construction and embodiment of gender, sexuality, and ability norms noted above (Bordo 1993; Butler 1993; Kirk 1999). In order to illuminate the regulation of the (gendered) body, yet also the possibilities for the shifting, crossing and transforming of boundaries (Barker Ruchti et al. this volume; Lamont and Molnàr 2002) we draw notably from French social theorist Pierre Bourdieu's (1985; 1993) tools of habitus, field and capital. Habitus, as the means by which society is 'written into' the body (Bourdieu 1990a), offers a way of understanding how social structures, norms and ideals can come to influence an individual's corporeal practice on an unconscious level. Habitus can be understood as a set of socially-constituted dispositions or tastes; subconscious schemes of perception and appreciation that collectively orchestrate practice (Bourdieu, 
1990b). These dispositions are afforded differing values (levels of capital) depending on the context, and serve to position individuals within a given field. Bourdieu highlighted three forms of capital: cultural, social and economic, to which Shilling (1991) added a fourth, physical. Applying Bourdieuian theories to sport and physical activity contexts, Shilling (1993) argued that the body becomes a reflexive 'project', with individuals working on the body in order to maximise the accumulation of physical capital and attain exchange value within relevant fields. In this way, the body comes to represent a site of both practice and power (Shilling, 1991) and the constant reproduction of gendered practice can lead to the embedding of discourses (including those of physical culture) through the habitus.

As lisahunter, Smith and emerald $(2014,3)$ argue, Bourdieu's work can be particularly useful in researching physical culture, as it helps to 'articulate the dialogue between structures that shape a society and their interaction with the individual person'. Physical culture can be understood as a complex, multi-dimensional site, comprising a number of key fields and sub-fields that interact and intersect in various ways (Bourdieu 1985). Bourdieu (1993) argued that the boundary of a field could be understood as being where the 'effects' of that field are felt. However, the boundaries between fields and sub-fields are often blurred and can represent points of disjuncture (Reay 2008). Although habitus can seem deeply embedded (Bourdieu 1990a), others have called for a more fluid approach (e.g. Robbins 2000), seeing habitus not as constraining an individual but as something they are able to manage in a more conscious way. If habitus can be reworked over time, then it is likely to reflect key differences within an individual's experiences, such as crossing the boundary between one field and another, where they have engaged in self-reflexivity (emerald and Barbour, 2014; Reay, 2004). This possibility for transformation resonates strongly with the context at the heart of this research and provides a valuable framework for understanding, in part, how the body-positive focus of an alternative dance community helps to facilitate and support individuals' construction of embodied identities. It is also very much in line with the strengths-based approach underpinning this research (Enright, Hill, Sandford and Gard 2014), which, in turn is driven by a desire to uncover 'what works' as the starting point for positive change and ongoing development.

\section{Methods}

Within this project we selected a qualitative case study approach to explore how bodypositivity was created and sustained within a dance community, using methodologies informed by appreciative inquiry (AI). AI can be perceived as an orientation to research and to change, underpinned by the belief that every culture, and every person in that culture, has strengths that should be the starting point for positive change (Cooperrider and Whitney 2001). It is based on the assumption that our research agendas determine what we discover. AI always begins with a positive question or an affirmative topic (Whitney and TrostenBloom 2010). Various typologies of the AI process have been outlined with the most popular model being Cooperrider and Whitney's (2001) 4D cycle: discover the best of what is, in 
order to then dream the best of what can be, design proposals for change based on common dreams, and realise a destiny by creating sustainable transformation. Following our identification of $\mathrm{AI}$ as an alternative approach to researching what works in physical education (Enright et al. 2014), we sought a case study with which we could work to investigate the best elements of a physical education-related positive movement subculture. The case presented here is a London-based dance school called Irreverent Dance (ID), which identifies as a body-positive space. It is a context in which teachers and learners have created their own meanings surrounding dance and dance education.

The research question guiding this project was: How do learners and teachers in Irreverent Dance create and maintain body-positivity? Prior to commencing the research fieldwork, full ethical clearance was obtained by the researchers and relevant processes relating to informing participants, obtaining consent and ensuring participant anonymity were followed. Participants agreed for the real name of the school to be used. While AI is not a technique or method, there are methods and questions which are more aligned with the approach. Positive comments are sought deliberately within applications of AI, but the aim is not to avoid being critical but to approach critique constructively, focusing on the positive elements already in practice. The specific methods used within this project are outlined below.

\section{Data sources}

Within the programme of research activities, five visits were made to ID so that the researchers could inform individuals about the project, ascertain their interest in being involved and arrange interviews. In addition, these visits allowed the researchers to observe a number of dance classes in action. In total, 12 participants (nine learners and three teachers) were interviewed using a semi-structured interview schedule inspired by AI, with positively framed questions. In this respect, the 4D approach proved valuable for guiding the writing of interview questions: for instance it was structured around discovering the positives of engagement in the dance classes (e.g. How/Why do you think this dance school is successful in engaging individuals in dance? What are your favourite aspects of the dance class?) and dreaming about developments in the dance school (e.g. What can you envisage other dance classes/movement classes learning from this one? What would you like to see yourself doing/achieving in terms of your movement experiences in the next few years?).

Each interview lasted between 30 and 60 minutes in length. The interviews were audio recorded and transcribed verbatim. It should be noted that only learners' interviews, not teachers', are quoted in the sections below and pseudonyms are used to ensure anonymity. Additional data sources (observation notes, the school's website, blog posts and magazine articles created by members of ID) were also collated, in order to provide additional context. Analyses of the verbal and visual data were undertaken to help construct narratives of the participants' experiences and highlight elements of practice and culture that were felt to contribute to a positive environment for movement. More specifically, the qualitative interview data were analysed using a thematic approach akin to constructivist grounded 
theory as described by Charmaz (2000). In this way, the individual interview transcripts were first reviewed and then analysed systematically by coding in stages (Strauss and Corbin 1998) until themes (drawn from common responses and areas of interest) were generated and verified. Moreover, in order to enhance validity and ensure inter-coder reliability (Miles and Huberman 1994) the initial coding of transcripts was done independently by two researchers before these analyses were shared and a consensus reached on the coding structure. The researchers then worked together to build up the core themes that emerged from the analysis. Following this, the core themes identified through the analysis were shared with learners and teachers (distributed in a report provided for the ID AGM) by way of a member check (Creswell and Miller 2000); helping to ensure the interpretation was meaningful to the participants.

\section{Crossing, shifting and transforming boundaries in Irreverent Dance}

Looking at 'what works' in ID provides us with a way to investigate and appreciate what people enjoy and achieve from their engagement in this movement subculture. Within this section, we highlight how this particular movement subculture created and maintained body positivity by considering how and to what extent boundaries around ballet, dance and gender/sexuality were shifted, crossed or transformed. Throughout these narratives we note some powerful epiphanies (emerald and Barbour, 2014) related to dance cultures, physical movement and identity.

\section{Crossing boundaries in dance: from unable to able, from non-dancer to dancer}

Celebrating body capability was an important element of ID participants' ('IDers') achievements in dance and an element of body-positive pedagogy that can be seen as a marker of crossing boundaries - and in some cases, transforming boundaries - in dance. There was a high level of celebration of what bodies can do, no matter their size, appearance or gender. This sense of achievement was expressed both in relation to specific ballet technique and in terms of general physical ability. Some of the achievement that Greg felt in this respect was highlighted in his reflections on the previous term's classes:

A lot of emphasis is put on how far you've come and in how much time and often what a short amount of time that is [...] they've had eight hours of formal training, look, now they're doing a dance.

Greg also commented on the physical sensation of dancing, suggesting that there is a sense of an improved awareness of the body through feeling or seeing limbs move, stretch and ache:

When you first watch it, it looks completely ungainly but then all of a sudden something clicks into place. It fits and it feels like a natural movement to make. 
At first, as Greg suggests here, dancers can feel as though they were putting the body on display and experience initial discomfort (Stahl 2013). Considering how far they have come is also an element of a reflexive process that assists in (re)developing a dance habitus (emerald and Barbour 2014). IDers were able to develop their dancing ability at a pace they were comfortable with, progressing gradually through ballet grades and repeating terms if they wished. Calling it 'a bit of reverse psychology really', Sal said:

Because [...] you can do it at your own pace, it makes me more likely to actually push myself and to make sure I go to classes. To make sure that I do my best.

According to the ID website, body-positive means a space in which people can learn without feeling like they are being judged; implying a place that is freer from sociallyconstituted corporeal norms and expectations. Members of ID certainly reflected this philosophy, although there were also often individual interpretations. Greg, for example, considered body-positivity to be simply about 'the joy in human movement'. Cath felt that 'it's sort of quite soothing, learning to do these things with your body', suggesting that physical learning is facilitated in a safe space. Similarly, Greg noted:

The thing that really draws people and engages them is when they're being shown that they can do a thing that they didn't even think was possible.

Muscularity and strength as examples of physical developments resulting from ballet training were celebrated as tangible or visible measures of the dancers' achievements. For example, Guy noted that 'my body is more useful than it was and it's something I did through dance'. Furthermore, celebrating her body's capability, Cath exclaimed:

It has really amazed me what my body can now do. I didn't know I could stand on my tip toes on one foot and swing my other leg round with my arm and, like, do it in a really controlled manner.

Others also expressed that they could forget everything else and concentrate by getting 'in touch' with their bodies. These connections were conscious attempts to think through the body and suggest that ID also offers a mental space in which to focus attention on the "whole me', as Cassie expressed it:

And it really helps you focus, because you just-everything else falls away, you're just thinking, where do my feet go for this exercise?

The learners' reflections suggest that understandings of the body as 'not capable' of doing something might have arisen in previous dance or movement experiences. Sal, for example, noted that in previous activity experiences she had felt 'your worth to the group depends on how well you do it', with a lack of ability (or physical capital) resulting in a perception of failure or feelings of 'I can't'. In ID, however, learners were actively encouraged to think 'I can' - reflecting the realisation that they were physically capable and would not be barred from dancing or performing. To borrow emerald and Barbour's (2014) 
language, when learners crossed into the ballet subfield of ID (a crossover of dance and LGBTQ fields) it was possible for positive elements (such as technical aspects) to be kept and more negative corporeal aspects (the valorising of slender, gender-normative or highlyable bodies) to be left aside. A key element of body-positivity, then, was encouraging revised perceptions of capability.

Physical changes to the body (and associated changes in perceptions of self) were celebrated and the gaining of a powerful physicality reconnected many dancers to their bodies. Some learners' relationship with themselves changed as a result of 're-finding' an identity as a dancer. For Greg, performing this identity as a dancer included dressing the part:

When I first started coming I started wearing like running gear and football shorts and stuff like that and I made a point of buying myself tights and shoes and a dance vest. Just to go, look, I'm a dancer, this is what you can wear [...] you know, dressing up as a dancer doesn't make you a dancer, but also it does legitimate - your interpretation of what you want to look like is part of legitimising yourself, there's that identity.

Sal explained that claiming an identity as a dancer was especially powerful for her:

So having a chance to take it back for myself and say no, this is who I am, this is how I am, this is how I want to be, is I mean, I can't even begin to explain how important it's been for me.

Sophy claimed that dancing enabled her to be 'comfortable and re-acquainted myself with my own body'. She expressed powerful feelings in accepting and celebrating a body that might previously have been 'something that let me down'. It suggests a disjuncture between habitus and field in other contexts (Reay 2008). Stahl (2013) argues that it is important to recognise that disjunctures can foster transformations and suggests that habitus only truly becomes transformative when the 'unthinking habitus' is jolted into consciousness (Reay 2004).

Owning an identity as a dancer was an important element of embodiment that could be gained by crossing into the ID space. Celebrating bodily capabilities appeared especially possible when dancers said that they were able to just 'be' in the ID space, where they have found the potential to become (re-)embodied. Sophy and Cassie explained what feeling disembodied felt like: '[not] feeling comfortable in my own skin' or 'see[ing] a stranger in the mirror'. Laura noted that this 'freeing' feeling was a part of the social environment created in ID, with a commitment to inclusion, respect and not judging others. As she stated, physically crossing into the subculture space, entering the ID studio,

leaves you free to focus on so many other things like actually learning the dance [...] it is like packaging up society's nonsense in a suitcase and leaving it by the door as you go in and then, okay, you might have to pick it up when you go out again, but hopefully not. 
The physical act of crossing into the ID dance studio was the entering into a designated dance studio, however there were some physical and pedagogical adaptations made to the space that marked some differences with other dance spaces and with non-dance spaces. A typical dance studio includes a mirrored wall that, as an instrument of surveillance, might encourage selfcriticism and discipline (Radell et al. 2014). In response, the ID teachers gave dancers a choice and a curtain was pulled halfway across the mirrored wall to assist. However, watching in the mirror might be a subversive act when physical strength rather than normative appearance is celebrated. Mirrors gave a strong visual feedback on body capability: 'you can look in the mirror and sort of think, god yes when I first started going to this I couldn't lift my leg that high' (Laura). Self-surveillance could contribute to reflexivity and the jolting into consciousness of the habitus (Reay, 2004). By adapting the dance environment, the boundary from body-negativity to body-positivity could be crossed, and potentially be a transformative experience.

\section{Transforming body-negativity into body-positivity}

Some participants identified that becoming an IDer had been a transforming experience in their relationship with their embodied self:

I actually quite like my body now, I don't think it's disgusting. That's quite a massive, massive turnaround. (Cath)

That's something that's been a really steep learning curve over the last few months, I've just started looking at myself completely differently and thinking - there is nothing to feel ashamed of, this is my body. (Cassie)

Learners noted how they were much more accepting of their bodies within ID, a key element of body-positivity. In one instance Sal highlighted feelings that it was she herself who could be in control of her body and identity, through dance:

It allows me to feel in control of my body and not let other people's thoughts and ideals that are put onto me from them affect me. [...] I can have control of my body as a person rather than thinking about how other people view me.

Cassie expressed that 'with the first five minutes of the first class, I just felt completely welcome and settled and like, this is where I want to be'. The teachers requested that everyone respect themselves as well as others. This was an epiphany for Cassie: realising that if you wouldn't judge someone else then you shouldn't judge yourself either. The values of supportiveness and respect for self and others were something explicitly created by the teacher at the start of the first class. This ensured that the boundaries of this specific context were recognised and understood.

The epiphanies experienced in crossing the non-dancer to dancer boundary have corporeal effects but, as the learners' language here suggests, these effects are transformative in terms of their relationships to themselves and their embodied identities. As noted earlier, 
feelings of physical incapability or aesthetic dislike of the body had been common bodynegative experiences that some IDers had felt in other dance or physical cultures. This was often grounded in perceptions that their bodies were too far removed from the 'ideal' within those contexts and therefore lacked physical capital. They framed their experiences in ID specifically in contrast to this. Offering a body-positive space may attract learners who have previously experienced a disconnection with their physical selves. The creation of a positive movement subculture seems then an act of resistance, in response to negative experiences influenced by rigid boundaries and adherence to heteronormative values in other contexts. emerald and Barbour $(2014,56)$ discuss the process of 'dance training as habitus' and make the point that 'the habitus of the contemporary dancer offers a reflexivity about self in relation to the world through training sensory awareness, embodied expression and presence - ultimately embodied ways of knowing'. The ballet training in ID encouraged reflexivity about the self and critique of the norms that had shaped learners' perceptions of their embodied selves within other dance contexts. In this way, it perhaps fostered a sense of disjuncture (Reay 2008) from the broader field of dance and opened up the possibility of transforming or interrupting the habitus (Gorely et al. 2003; Stahl 2013) through encouraging more conscious reflection on the norms and ideals that are used to shape practice.

\section{Transforming gender/sexuality boundaries through gender-neutrality}

Levels of awareness of the body were particularly articulated concerning dancer identities, as noted above, but also with gender identities and expressions. All learners valued the relationships they developed within and beyond classes, suggesting that the sharing of values (particularly the redefining of corporeal norms) promoted inclusivity and safety. Diversity was a key element of the community. As Laura articulated:

[We] might feel like a bit of a misfit for one reason or another but get all of us in a room together and we're not misfits anymore because we all fit because we don't if you see what I mean.

By promoting difference, difference mattered less. However, neither were learners and teachers who were white, cissexual, heterosexual and/or male made to feel excluded due to their privilege, as Greg pointed out:

Nobody is excluded [...] Which is not a trivial concern, because I'm a straight male, and I am the scary person for most people who have any kind of lack of privileges, I am the threat [but] I am expressly welcome. [...] It is something that's seen as a safe space [...] and that's really a welcome thing - that it's not a space for everyone but me (emphasis in original).

Gender boundaries within and around sports cultures can be particularly durable (Berg and Lahelma 2010; Wellard 2006). Challenges to these boundaries can be especially transformative. Against ballet's typically gendered spaces and structures, ID outlined a 
commitment to personal choice in gender presentation, so that each dancer could decide what was comfortable for them. Sophy explained:

People [are] doing it because they want to and doing the things that they feel comfortable doing, regardless of who's supposed to be doing them, you know no one's just doing the boy steps because they're boys, people are doing the men's steps because they like jumping and they enjoy the strength and the freedom that you can get from that.

Elements of dance that have typically gendered boundaries were resignified; for example, men were invited to learn to dance en pointe if they wished. Dancers commented that their perception of what their bodies could do developed positively when heteronormative and cisnormative boundaries (in dance movement and performance) were eliminated. This is a powerful element in reflecting that it may be gender normativity in other fields that restricts positive movement experiences, as Lizzie's explanation of gender-neutrality and LGBTQfriendly indicates:

Nobody's going to be sort of, assuming anything about anybody, or guessing anybody's gender or assuming that somebody doesn't want to be the size they are and would rather be a different size.

On the other hand, Sal noted that she was able to feel feminine in ID classes, something that she had not been able to achieve before. Similarly, for Laura,

I'd always just thought, well I'm not graceful so ballet's not for me, it never occurred to me, of course ballet teaches you to be graceful, so that I think sold it to quite a lot of us that [the teacher] could teach us to be the graceful coordinated creatures we never thought we were.

Sal and Laura's comments appear to be reifying gender by re-centring feminine and graceful aesthetics in their performance of ballet bodies. However, they were empowered within ID to embody identities that they had not previously perceived as being open to them; their physical capital lacking exchange value (Shilling 1993) within the broader field of dance. Physical capital in femininity has been fundamentally linked to body size as well as aesthetics - not only conventionally attractive but slender (Bordo 1993). Far from prohibiting any gender identity, gender-neutrality in the dance space signified transgression by valorising fat or non-gender-normative bodies as graceful. Sal and Laura actively seek to experience an embodiment not accessible to them before. Drawing from Sykes' (2011) discussion of fat bodies as queer adds a further dimension to the normalised body in the sex-gender-sexuality constellation (Youdell 2005). Fat female bodies have been objectified as not feminine (or heterofeminine), partly because fat, like butch, appears to contest desirability only being possible in slender and heterofeminine women. By identifying non-normative bodies as capable and valued (redefining their physical capital) these participants rewrote what could be read as a ballet body in their eyes. As Sykes and MacPhail (2008) argue, fat subjectivities 
can be validated with inclusive curricula and pedagogies. Nevertheless, drawing from Butler (1993), they note that because those subjectivities were formed in resistance to dominant slender norms, they remained limited by the dominant discourses that produce their agency. While boundaries might be transformed or even erased within the ID space, learners could not help but be aware of how gender and other body norms affect their lives beyond the studio.

\section{Shifting the boundaries of a codified dance: challenging ballet norms}

A central element in the learning and community of ID was deconstructing ballet's gender boundaries; challenging dominant notions about what gendered ballet bodies look like, what they should do and what progress must be made. Some learners reflected on how they had been looking for a dance class that would suit their 'uncoordinated', 'geeky back of the class loner' or 'fat' bodies. These were feelings they claimed to have experienced in other dance classes at both novice and elite level, which is indicative of a physical culture of restrictive embodied and gendered boundaries in mainstream ballet. The learners' perceptions were that their own bodies did not 'fit' inside these traditional boundaries because of both ability and aesthetic norms. Technical aspects were taught but Emma noted that the ID teachers adapted them for different bodies and capabilities:

Obviously a lot of ballet schools would [say this is] not good enough because you're not doing the exercise in the official proper way, but [ID says] as long as you're doing it and you're making the effort to do it as well as you can, that's what matters.

Emma's perceptions of the technical progress that ballet dancers should make are affected by the social construction of dancing as requiring years of discipline and sacrifice (Aalten 2007). Laura's views of ballet, even beginners' classes, had also been that it was 'really intimidating for people that weren't natural dancers or that weren't natural exercisers'. ID aimed to deconstruct 'natural' ability with learners encouraged to see themselves as capable of moving and stretching as ballet requires. What constitutes dancing or a dancer, at least in the eyes of the learners, was challenged by ID. Ballet norms in the sense of technical requirements, language, music and dress styles were recognised (those boundaries only shifting) but with gender boundaries transformed this meant that learners who would previously have not had access to ballet (been 'in' ballet) could find a space that was safe and positive for them. Although risking a critique of the broader physical culture of ballet, by centring the IDers' narratives we recognise that their habitus was developed in part as a reaction to other ballet spaces. While dancer and gender identity boundaries were crossed or transformed respectively, ballet boundaries were only shaken or shifted somewhat, remaining largely in place.

\section{Conclusion}


Individuals in ID were encouraged to challenge dance and gender norms by experiencing and becoming a part of a community that focused learning around creating body-positivity. This led to many IDers redefining their perceptions of body capability and worth; empowering them to transform gender boundaries and enabling them to claim an identity as a dancer. In this way, ID represented a point of disjuncture (Reay 2008) for many and offered the opportunity to begin a transformation of habitus through revising the schemes of perception and appreciation that shaped their practice (Stahl 2013). Crossing into the ID space allowed individuals to shift into a landscape with redefined boundaries, in which alternative perspectives on bodily appearance, capability and worth (physical capital) were possible.

ID, then, could be considered a 'border space' (Sastre 2014) within the fields from which it and its participants draw; a space that is in flux in different ways for different participants (Bourdieu 1984; lisahunter 2014) as it is constructed and bounded by its relations to other fields, including ballet, dance, LGBTQ and fat activism. ID redefined traditional boundaries (e.g. relating to gender roles, body norms and ability) to facilitate access, but maintained some observance of the values of style and technique in ballet. Non-genderconforming dancing bodies could be able, strong and graceful, deconstructing the traditional habitus of a dancer. As such, traditional symbolic boundaries of ballet are retained but social boundaries are dismantled (Lamont and Molnàr 2002). The focus on individual worth is significant here, because it allows for physical capital to have an 'exchange value' (Shilling 1993) that is specific to each dancer, which helps to underpin the concept of a body-positive approach. Adjusting their thinking to fit these redefined boundaries allowed many learners in ID to find a reconnection with their own body and begin a process of 'interrupting' their habitus; challenging accepted norms regarding gendered bodily ideals and practices and opening their eyes to new possibilities. Arguing for a gender-relevant physical education, Gorely et al. (2003) contend that the de-stabilising of stereotypical femininities and masculinities is necessary in order to facilitate the empowerment of all. Similarly, the challenging and redefining of boundaries around ballet, dance and gender/sexuality within ID can be seen to empower individuals through facilitating their access to and achievement within a physical culture that would otherwise marginalise them.

While ID was successful in creating and maintaining body positivity, however, it is worth noting that in other movement subcultures the possibilities may look different because of alternative field configurations. Nonetheless, it would seem that a body-positive approach is important as a means of transforming boundaries around dance movement, gender expression and the body; legitimising individuals' practice within the shared understanding of a meaning intensive movement subculture (Kretchmar 2000). This is integral to how ID supports learning and might go some way to redefining the gender boundaries and body work that have been necessary in physical cultures.

\section{References}


Aalten, A. 2004. "The moment when it all comes together': Embodied experiences in ballet". The European Journal of Women's Studies, 11(3): 263-276.

Aalten, A. 2007. "Listening to the dancer's body". The Sociological Review, 55: 109-125.

Bartlett, K. 1996. "Community dance and politics." In Thinking Aloud: in Search of a Framework for Community Dance, edited by C. Jones, 15. Leicester: Foundation for Community Dance.

Berg, P., \& Lahelma, E. 2010. "Gendering processes in the field of physical education." Gender and Education, 22(1): 31-46.

Bordo, S. 1993. Unbearable weight: Feminism, western culture and the body. London: University of California Press.

Bourdieu, P. 1985. "The social space and the genesis of groups". Theory and Society 14(6): 723-44.

Bourdieu, P. 1990a. In other words: Essays towards a reflexive sociology. Cambridge: Polity Press.

Bourdieu, P. 1990b. The Logic of Practice. Stanford University Press.

Bourdieu, P. 1993. Sociology in Question. London: Sage.

Burgess, G., Grogan, S. and Burwitz, L. 2006. "Effects of a 6-week aerobic dance intervention on body image and physical self-perception in adolescent girls." Body Image 3: 57-66.

Butler, J. 1993. Bodies that matter. London: Routledge.

Butler, J. 1998. "Athletic genders: Hyperbolic instance and/or the overcoming of sexual binarism”. Stanford Humanities Review 6(2): 103-111.

Charmaz, K. 2000. "Grounded theory: Objectivist and constructionist methods." In Handbook of qualitative research, 2nd ed, edited by N.K. Denzin and Y.S. Lincoln, 509-36. London: Sage.

Connell, R. W. 1995. Masculinities. London: Polity Press.

Cooperrider, D., and Whitney, D. 2001. "A positive revolution in change: Appreciative inquiry." In Appreciative inquiry: Rethinking human organization towards a positive theory of change, edited by D. Cooperrider, P. F. J. Sorensen, D. Whitney and T. F. Yaeger, 3-26. Champaign, IL: Stipes Publishing.

Creswell, J. W. and Miller, D. L. 2000. "Determining validity in qualitative inquiry." Theory into Practice 39(3): 124-131. 
emerald, e. and Barbour, K. 2014. "'I'll go back next week - it's complicated'. Returning to dance with the help of Bourdieu." In Pierre Bourdieu and Physical Culture, edited by lisahunter, W. Smith \& e. emerald, 27-36. London: Routledge

Enright, E., Hill, J., Sandford, R. and Gard, M. 2014. "Looking beyond what's broken: Towards an appreciative research agenda in PESP." Sport, Education and Society 19 (7): 912-926.

Erfer, T. and Ziv, A. 2006. "Moving towards cohesion: Group dance/movement therapy with children in psychiatry." The Arts in Psychotherapy. 33: 238-246.

Gorely, T., Holroyd, R. and Kirk, D. 2003. "Muscularity, the habitus and the social construction of gender: Toward a gender relevant physical education." British Journal of Sociology of Education 24: 429-448.

Hargreaves, J. and Vertinsky, P. 2007. Physical culture, power and the body. London and New York: Routledge.

Houston, S. 2005. "Participation in community dance: A road to empowerment and transformation?" New Theatre Quarterly 21 (02): 166-177.

Kirk, D. 1999. "Physical culture, physical education and relational analysis." Sport, Education and Society 4 (1): 63-73.

Kretchmar, R. S. 2000. "Movement subcultures: sites for meaning." Journal of Physical Education, Recreation and Dance 71 (5): 19-25.

Lamont, M., and Molnàr, V. 2002. "The study of boundaries in the social sciences". Annual Review of Sociology, 28, 167-195.

Langdon, S. W., and Petracca, G. 2010. "Tiny dancer: Body image and dancer identity in female modern dancers." Body Image 7(4): 360-363.

lisahunter, Smith, W. \& emerald, e. 2014. Pierre Bourdieu and Physical Culture. London: Routledge.

Miles, M. B., and Huberman, A. M. 1994. Qualitative data analysis: An expanded sourcebook. 2nd ed. Thousand Oaks, CA: Sage Publications.

Peppiatt, A. 1996. "The voice of lost and drifting generations: An enquiry into the meaning and value of community dance," Research Papers on Community Dance 2: 8-9.

Radell, S. A., Keneman, M. L., Adame, D. D., and Cole, S. P. 2014. "My body and its reflection: A case study of eight dance students and the mirror in the ballet classroom". Research in Dance Education, 15(2): 161-178.

Ravaldi, C., Vannacci, C., Bolognesi, E., Stafania, M., Faravelli, C. and Ricca, V. 2006. "Gender role, eating disorder symptoms and body image concern in ballet dancers." Journal of Psychosomatic Research 61: 529-535. 
Reay, D. 2004. "“It's all becoming habitus' beyond the habitual use of habitus in educational research", British Journal of Sociology of Education, 25(4): 431-444.

Reay, D. 2008. "Class out of place: The white middles classes and intersectionalities of class and "race" in urban state schooling in England". In The Way Class Works, edited by L. Weis, 87-100. New York: Routledge.

Risner, D. 2002. "Re-educating dance education to its homosexuality: An invitation for critical analysis and professional unification". Research in Dance Education, 3(2): 181187.

Robbins, D. 2000. Bourdieu and Culture. London: Sage Publications.

Sastre, A. 2013. "Towards a radical body positive: reading the online 'body positive movement"”. Feminist Media Studies, 20(3): 929-943.

Shilling, C. 1991. "Educating the body: Physical capital and the production of social inequalities.” Sociology 25 (4): 653-672.

Shilling, C. 1993. The body and social theory. London: Sage Publications.

Stahl, G. 2013. "Habitus disjunctures, reflexivity and white working-class boys' conceptions of status in learner and social identities," Sociological Research Online, 18(3): 2.

Strauss, A.L. and J. Corbin. 1998. Basics of qualitative research: Techniques and procedures for developing grounded theory. 2nd ed. Thousand Oaks, CA: Sage.

Sykes, H. 2011. Queer bodies. New York: Peter Lang.

Sykes, H., and McPhail, D. 2008. "Unbearable lessons: Contesting fat phobia in physical education.” Sociology of Sport Journal, 25, 66-96.

Wellard, I. 2006. "Able bodies and sport participation: social constructions of physical ability for gendered and sexually identified bodies". Sport, Education and Society, 11(2), 105119.

Wellard, I., Pickard, A., and Bailey, R. 2007. "A A shock of electricity just sort of goes through my body': Physical activity and embodied reflexive practices in young female ballet dancers". Gender and Education, 19(1): 79-91.

Whitney, D. and Trosten-Bloom, A. 2010. The power of appreciative inquiry. San Francisco: Berrett-Koehler Publishers.

Youdell, D. 2005. "Sex-gender-sexuality: how sex, gender and sexuality constellations are constituted in secondary schools." Gender and Education, 17(3): 247-270. 